\title{
LA-UR-15-26700
}

Approved for public release; distribution is unlimited.

Title: $\quad$ Business Case Analysis for In-Vessel Composting at the TA-46 SWWS Facility

Author(s): $\quad$ Dinehart, Timothy Grant

Intended for: Report

Issued:

2015-08-25 
Disclaimer:

Los Alamos National Laboratory, an affirmative action/equal opportunity employer,is operated by the Los Alamos National Security, LLC for the National NuclearSecurity Administration of the U.S. Department of Energy under contract DE-AC52-06NA25396. By approving this article, the publisher recognizes that the U.S. Government retains nonexclusive, royalty-free license to publish or reproduce the published form of this contribution, or to allow others to do so, for U.S. Government purposes. Los Alamos National Laboratory requests that the publisher identify this article as work performed under the auspices of the U.S. Departmentof Energy. Los Alamos National Laboratory strongly supports academic freedom and a researcher's right to publish; as an institution, however, the Laboratory does not endorse the viewpoint of a publication or guarantee its technical correctness. 


\section{Business Case Analysis for In-Vessel Composting at the TA-46 SWWS Facility}

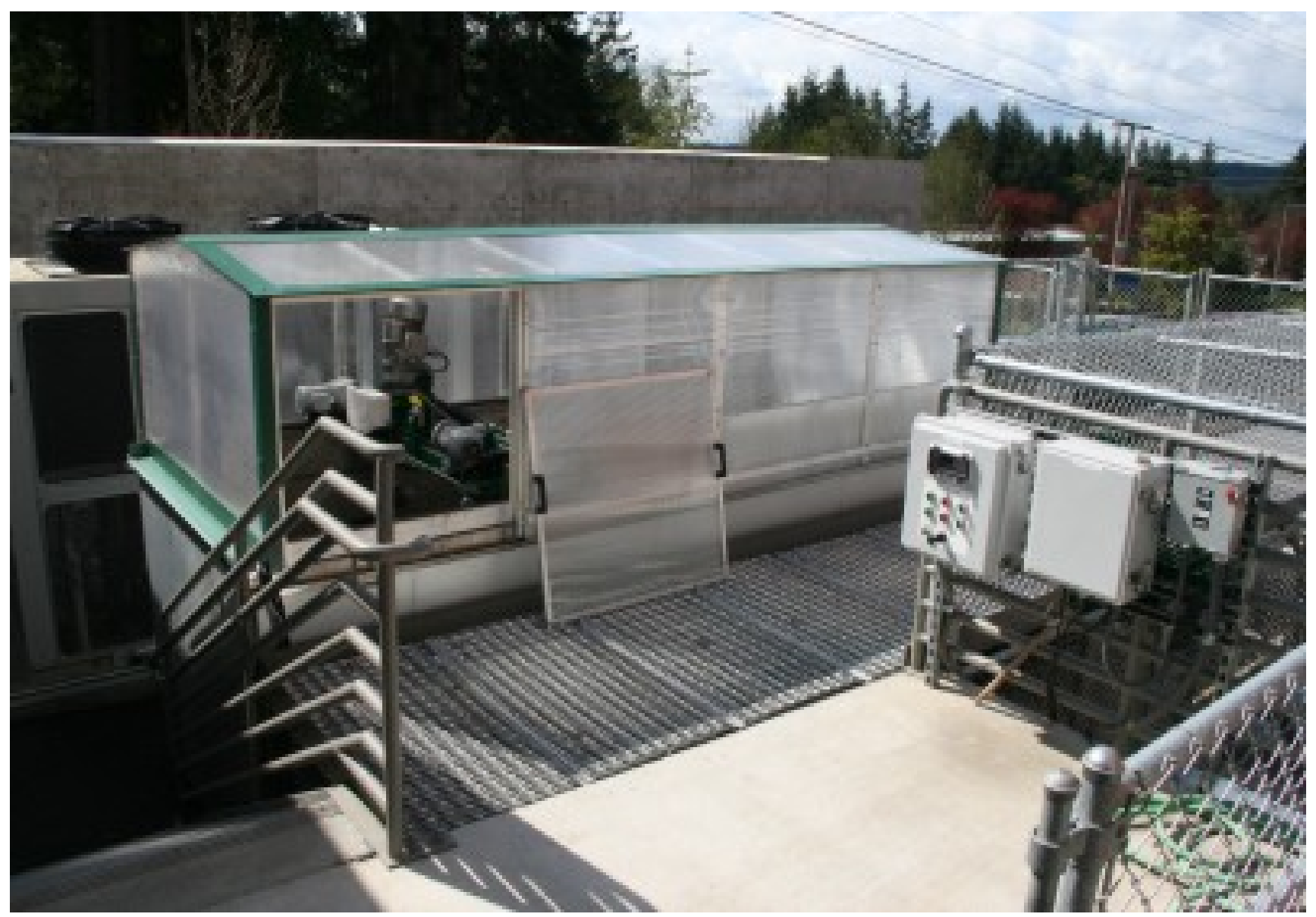

Tìmothy G. Dinehart

August 2015 


\section{Cover Illustration:}

\section{Front Cover - Example of the Earth Flow In-Vessel Composting System}

\section{http://compostingtechnology.com/wp-content/uploads/2012/10/earth flow.jpg}

Los Alamos National Laboratory, an affirmative action/equal opportunity employer, is operated by the Los Alamos National Security, LLC for the National Nuclear Security Administration of the U.S. Department of Energy under contract DE-AC52-06NA25396. By acceptance of this article, the publisher recognizes that the U.S. Government retains a nonexclusive, royalty-free license to publish or reproduce the published form of this contribution, or to allow others to do so, for U.S. Government purposes. Los Alamos National Laboratory requests that the publisher identify this article as work performed under the auspices of the U.S. Department of Energy. Los Alamos National Laboratory strongly supports academic freedom and a researcher's right to publish; as an institution, however, the Laboratory does not endorse the viewpoint of a publication or guarantee its technical correctness. 


\section{TABLE OF CONTENTS}

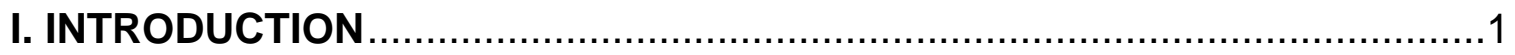

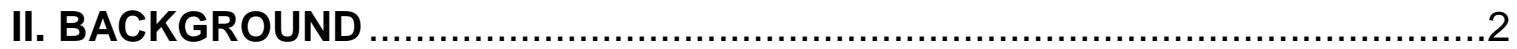

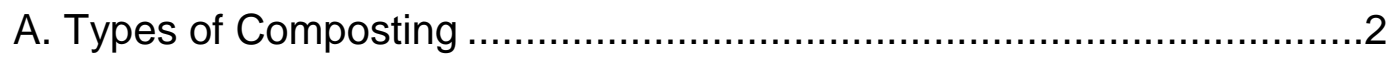

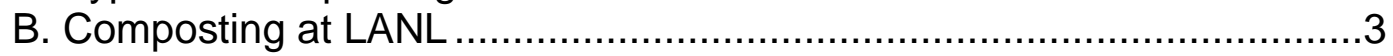

III. METHODOLOGY

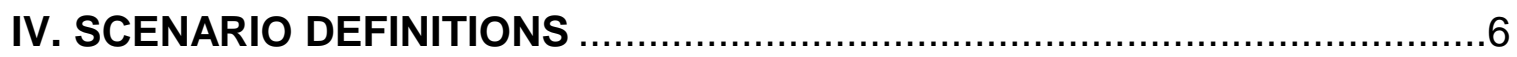

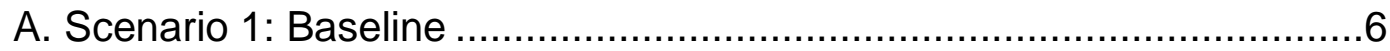

B. Scenario 2: Earth Flow System with Current Input.............................6

C. Scenario 3: Earth Flow System with Ideal Input.................................

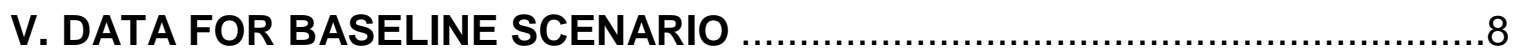

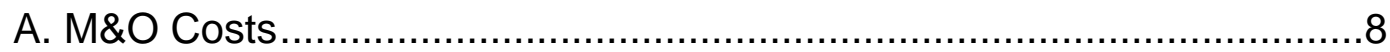

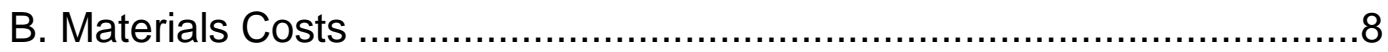

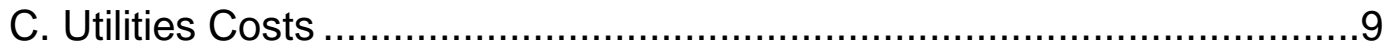

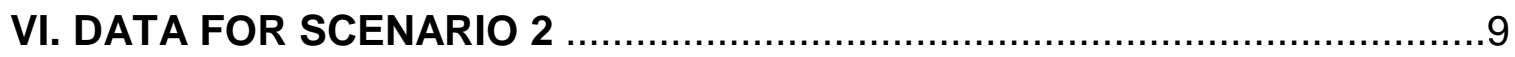

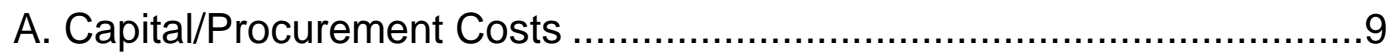

B. Installation \& Transition Costs ..........................................................

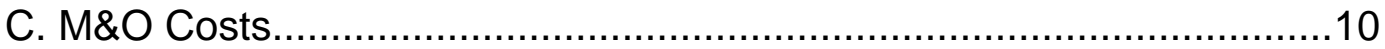

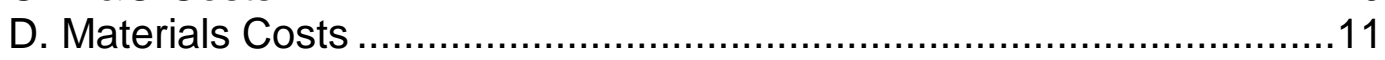

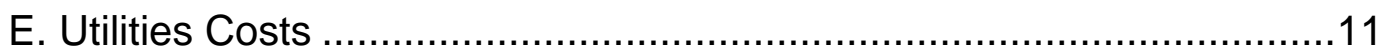

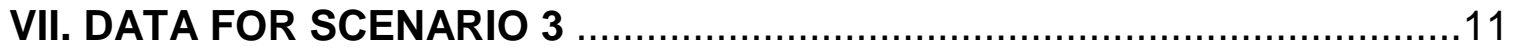

A. Capital/Procurement/Installation \& Transition/M\&O Costs .................11

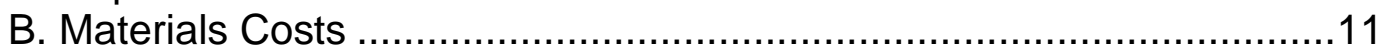

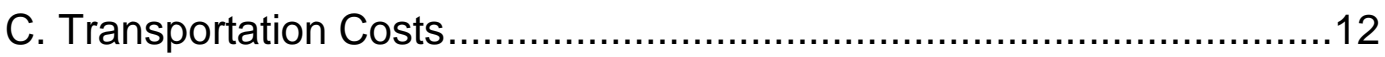

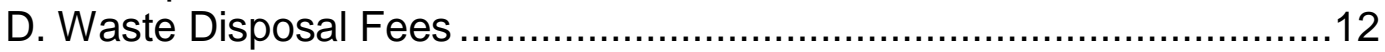

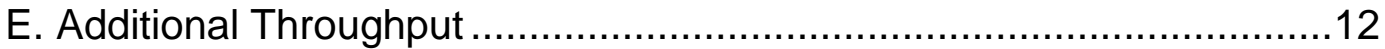

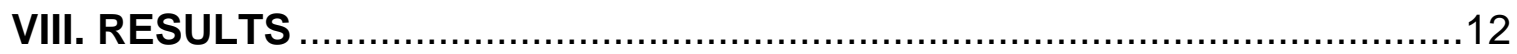




\section{LIST OF FIGURES}

1. Windrows at the SWWS Compost Facility..............................................

2. Example of In-Vessel Composting with Auger .............................................

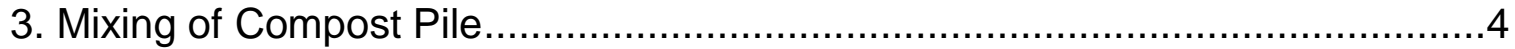

4. Total LANL Waste Stream for Three Scenarios .........................................

5. Payback Period and Net Present Value for Scenario 2 ..............................16

6. Payback Period and Net Present Value for Scenario 3 ..............................17

\section{LIST OF TABLES}

1. Assumptions and Factors for Life Cycle Analysis.......................................13

2. Life Cycle Benefits and Costs for Scenario 2 Compared to Scenario 1...........14

3. Life Cycle Benefits and Costs for Scenario 3 Compared to Scenario 1...........15 


\section{INTRODUCTION}

Over the last half century, a movement towards greater accountability and responsibility for the environment has grown within the United States. While conservation efforts have existed as part of the national agenda since the time of Theodore Roosevelt, communities around the country are beginning to see greater value in efforts to recycle waste, recognizing that these endeavors aid in reducing consumption of resources and eventually yield certain monetary benefits. City government efforts in San Francisco, California and college programs by Cornell and Bates College have both seen considerable success in moving treatable waste away from landfills through a variety of composting programs. ${ }^{12}$

The Zero Waste Initiative is a long-term project at Los Alamos National Laboratory (LANL) with an eventual goal of achieving 90 percent landfill diversion. This goal can be achieved through gradual, proactive steps involving recycling, reusing, and composting different waste materials around the lab. Composting biowaste is a particularly important element of this plan due to the potential increases in greenhouse gas emissions that come from placing organic materials in landfills and the misallocation of resources involved in the process when viable alternatives exist. ${ }^{3}$ The initiative itself is an important focus for the lab's commitment to Environmental Sustainability, and also represents LANL’s commitment to responsible environmental stewardship as it continues pursuing its strategic objectives.

As part of this greater effort, the Sanitary Wastewater System (SWWS) Compost Facility was established and approved by the New Mexico Environment Department's (NMED) Solid Waste Bureau in March of 2014. This facility, operating in conjunction with the current waste water treatment facility at TA-46, converts biosolid waste produced during the sanitation process into a form of compost that can be utilized around LANL. The facility uses a method called aerated static pile composting. Organic waste taken from the sanitation facility and other departments around the lab is distributed into long rows and aerated through the usage of a bulking agent (woodchips and sawdust in this case). Over time, the pile bakes and slowly decomposes into suitable, EPA-approved compost. While the current system is in its early stages, potential improvements are already being considered as the program expands to include other forms of waste (including pre-consumer and post-consumer food scraps, paper towels, and other materials that will be discovered as usage increases). These larger scale investments are a necessary consideration, as many of the future inputs cannot be reliably handled in the current process.

The purpose of this Business Case Analysis is to weigh the potential costs and benefits of installing an In-Vessel Composting system at the SWWS Compost Facility. In-vessel composters are designed to be maximally proficient with composting food waste, and have advantages with regards to the speed of composting and control over various inputs. However, there are capital costs associated with this system that must be compared against any potential savings accrued through increased efficiency.

\footnotetext{
${ }^{1}$ http://www.bpiworld.org/page-190309

2 http://compost.css.cornell.edu/Cornell.html

${ }^{3}$ http://compostingcouncil.org/admin/wp-content/uploads/2011/11/Keeping-Organics-Out-of-Landfills-PositionPaper.pdf
} 


\section{BACKGROUND}

\section{A. Types of Composting}

Composting waste for larger scale facilities can be accomplished in a variety of ways. The two types of compost management pertinent to this study are aerated static pile composting and invessel composting. In the current system of aerated static pile composting employed at LANL, the sludge waste produced at the Water Treatment Facility is first mixed with both lab-produced green waste and woodchips conveyed from Espanola. These substances are mixed into the pile to provide crucial nitrogen and carbon sources for the composting process. The mixed pile is subsequently laid out in a long mound, known as a windrow, on a sand bed where it slowly "bakes.” (See Figure 1) The baking process involves microbes decomposing the various products in the mixture, with temperatures reaching in excess of 120 degrees Fahrenheit as a byproduct of this breakdown. Once the pile has significantly decomposed over the course of approximately two to three months, samples are taken to determine the quality of the new compost.

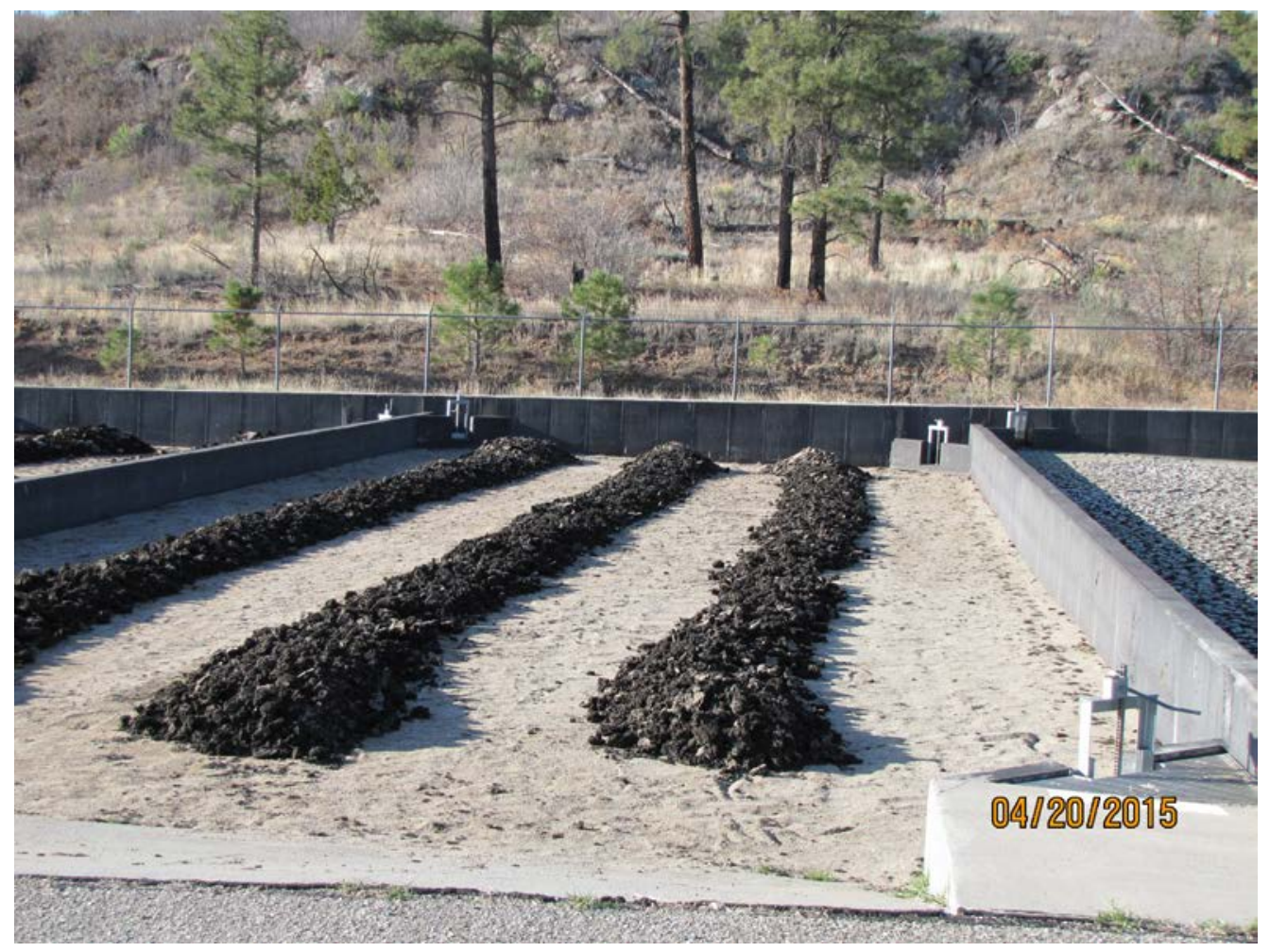

Figure 1: A set of windrows compiled of the sludge/sawdust/greenery mixture lie baking at the SWWS Composting Facility. The windrows are laid out on sand beds to bake.

One difficulty with this set-up involves separating the windrows from the underlying sand beds after significant decomposition has occurred. The Operations Division (UI-OPS) considered the costs of permitting and installing concrete beds at the composting Facility, but deemed the cost/benefit scenario to be unsatisfactory. ${ }^{4}$

\footnotetext{
${ }^{4}$ Randy Vigil, personal communication, 5/18/2015
} 
With an in-vessel composting system, the various materials utilized for the process remain the same, but they are instead fed into a dedicated vessel. The vessel is useful in that it provides close control over various conditions including moisture, temperature, and aeration. It also provides security when considering possible intrusion by the wildlife in the area. This has been a major limitation on the current composting facility. Potentially the most useful part of many of these systems is that they contain a mixing apparatus (oftentimes an auger) that will continuously mix the pile while also breaking up any parts that may not be decomposing consistently. This speeds up the composting process significantly with some batches taking only a few weeks to

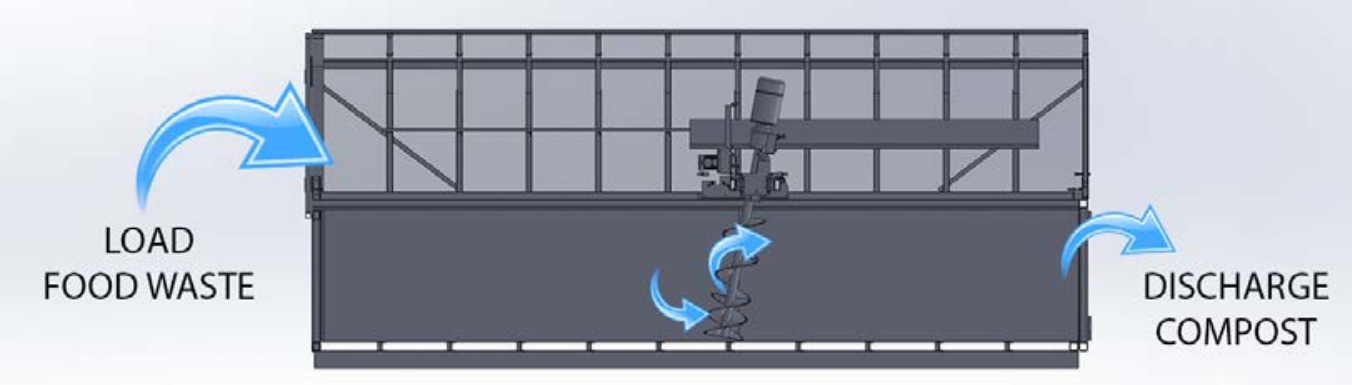

\section{Figure 2: An example of the in-vessel composting system being considered for this project. The auger in the center of the image is crucial for the speed of the decomposition process.}

decompose. ${ }^{5}$ In-vessel composting systems are also the preferred method for handling food waste material, making it an appealing alternative to handle the expected expansion of the LANL composting initiative.

\section{B. Composting at LANL}

Waste minimization has been a major concern for both national laboratories in New Mexico during the last decades. Los Alamos National Laboratory and Sandia National Laboratories (SNL) provide notable benefits on a state and national level. However, they also have sizable environmental footprints. The efforts to engage in recycling and composting behaviors at both labs are leading factors in the attainment of greater long-term goals of landfill diversion. Sandia's efforts have been aided by its partnership with Kirtland Air Force Base and a composting program that began in March of 2010 to divert food preparation waste and leftovers from the regular waste stream. ${ }^{6}$ After a successful pilot program diverted more than 15,000 pounds of wet food waste from the landfill during a six-month period, the plan was adopted throughout Sandia. SNL has also had an advantage in that it is able to use money garnered from its recycling activities to help fund its programs. The success of the program at Sandia serves as a benchmark by which Los Alamos National Laboratory can compare its own program.

At LANL, increases in composting activity began several years later with the opening of a composting facility in March of 2014. This effort, organized at the TA-46 SWWS Facility, has proven to be largely successful in creating savings for the laboratory. Currently, the composting facility's main purpose has been to provide an ancillary function for the water treatment process.

\footnotetext{
${ }^{5}$ http://www.epa.gov/composting/types.htm

${ }^{6}$ https://share.sandia.gov/news/resources/news_releases/from-fork-to-farm/\#.VZGjHEY3k6U
} 
In this capacity, it has helped generate cost savings through diversionary action while providing an environmentally responsible and useful way of dealing with the biosolid byproducts of the lab. According to initial reporting included in a 2015 Pollution Prevention Award nomination, composting this facility's biosolids instead of engaging in extra, costly procedures to properly dispose of the waste elsewhere has saved the lab upwards of \$330,000 to date. ${ }^{7}$ The initial batches of compost created using the facility waste have been shown to meet EPA standards by Hall Environmental Analysis Laboratory.

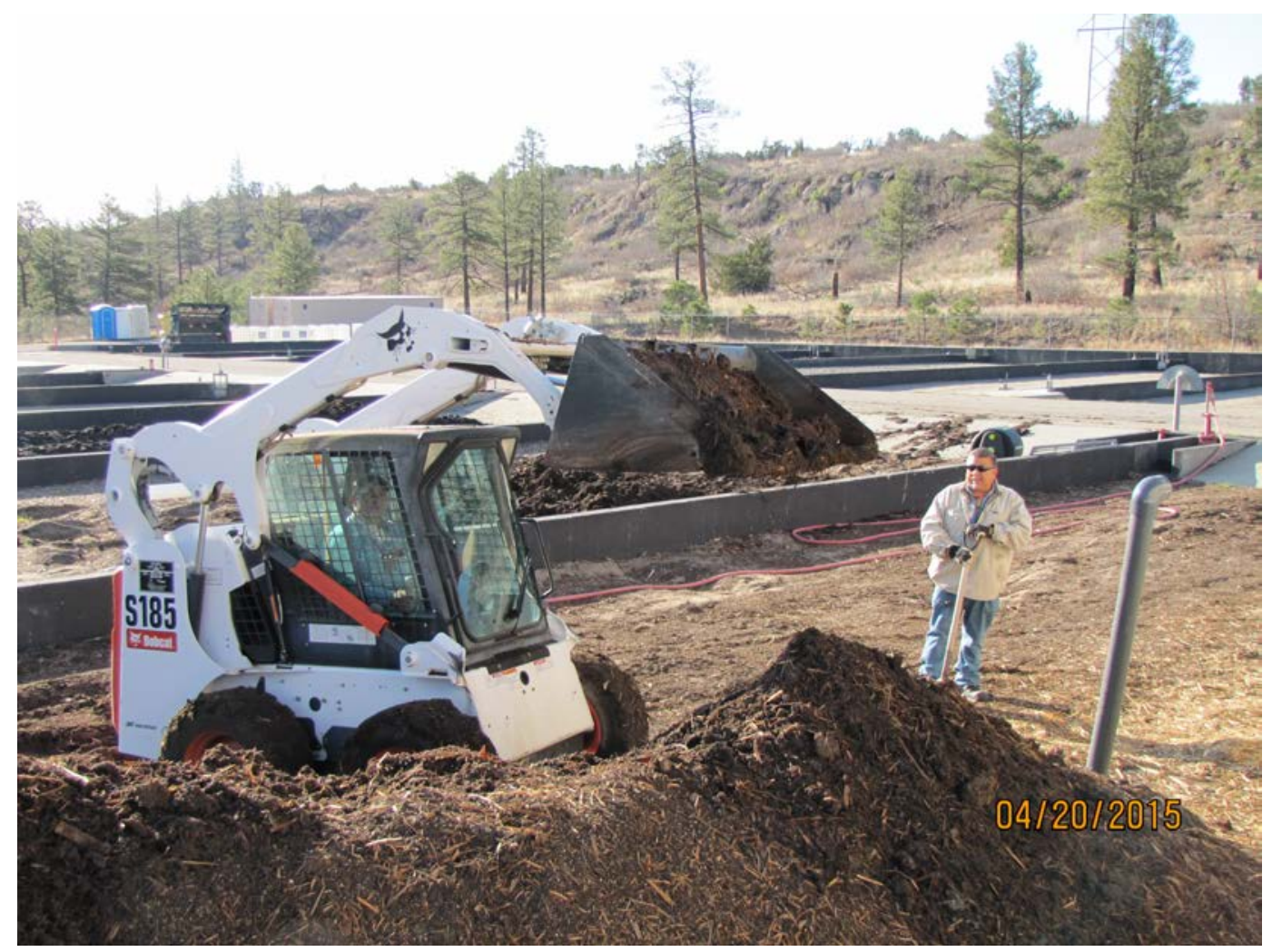

Figure 3: Operator Foreman Gerald Marquez and Operator Isaiah Medina work to mix compost at a later stage of the composting process. The tube seen on the far right was used as part of an experiment in aeration.

In conjunction with the Zero Waste Initiative and potential public relations gains, the compost generated by LANL operations will have other economic benefits for the laboratory. One example is that the compost will be perfectly suited for erosion socks in erosion retention areas on LANL property. ${ }^{8}$ These socks will help prevent any harmful runoff while also replenishing nutrient dense soil in the area as the socks degrade. Labor is also saved because the socks do not have to be removed later as the compost produced by LANL is permitted to be disposed in the soil. Compost from the facility can also be used for remediation efforts on burned land or areas cleared of waste. These examples show that there is a demand for the material currently

\footnotetext{
${ }^{7} 2015$ Pollution Prevention Award Nomination, Randy Vigil, 3/2/2015

${ }^{8}$ John David Naranjo, personal communication, 5/27/2015
} 
produced at the SWWS Composting Facility, and that there will probably be increasing demand for further compost as the project expands in scope.

An extremely important aspect of this study is that the savings acquired by the current composting system at TA-46 are only considered in qualitative rather than quantitative terms. This is due to a needed caution when discussing the merits of a new technology. This report is analyzing the singular value of adding an in-vessel composting system to the lab's current arsenal of environmentally friendly capabilities. All improvements made before the addition of this system are included as part of a baseline scenario so as not to bias results. This keeps past savings or costs from "piggy-backing" on the item in question. However, this does not mean that the in-vessel composting system case exists in a vacuum. The progress seen by the current composting facility at the lab should not be ignored as it shows how expansion of zero waste capabilities can have profound effects that are both economically successful and pragmatic when considering the lab’s long-term objectives.

The concerted effort to establish an in-vessel composting system at LANL stems from the limitations that aerated static piles impose upon further expansion of the program. Adding food scrap to the waste stream generates a number of extra variables that must be considered for safety along with the logistics of actual composting. Considering the lab's location, a prevalence of wildlife could interfere with the piles and, depending on the type of animal, put the composting crew in danger. Furthermore, new surface water complications emerge with the addition of any new inputs to the current stream. Any plans of expansion are at a standstill until an in-vessel composting system is considered.

\section{METHODOLOGY}

The business case methodology used here is based on comparing a baseline scenario ("the world that exists today") with a future scenario that could exist if the in-vessel composting unit is purchased and installed. The conditions under the two scenarios are defined via interviews with various subject matter experts in terms of one-time and periodic costs, and annual costs associated with running the project. The performance of the composting facility is predicted based on the recent history of work at the facility along with the expected expanded work at the facility. Costs that could be avoided by the use of the new equipment and other benefits, such as improved ability to handle different kinds of waste more efficiently, are also considered.

By comparing the future scenario with the present, a picture of the potential savings is formed. The most important consideration in a business case is usually in the form of "productivity improvement" savings. This value is computed by looking at the costs used to handle a certain amount of waste in the "existing world" and the lower amount needed for the same operation in the "future world." By finding this, the analysis is able to account for an increase in usage of the newer system without penalizing it for the added costs of an increased workload. Instead, the productivity savings delta reflects the time and energy saved when comparing the new and improved output to what it would have cost in the baseline scenario. 


\section{SCENARIO DEFINITIONS}

To properly determine the value of a new system, a number of scenarios must first be defined. A baseline scenario is needed for comparison purposes, and a number of other scenarios must reflect the intended changes associated with the project. Originally, the baseline scenario was expected to be a reflection of the costs associated with taking all waste to the county dump prior to the opening of the Compost Facility. However, this serves as an unfair representation of what the added In-Vessel Composter will bring in value. Since the Compost facility has already been established and opened, it acts as a sunk cost and the savings associated with its initial implementation should not be considered in the calculations for the new project.

\section{A. Scenario 1: Baseline}

The baseline scenario for this analysis consists of the current costs associated with the SWWS Compost Facility. Included are data on maintenance and operational costs associated with running the facility, material costs, and any additional utility costs for proper composting.

According to an annual report required by the New Mexico Environment Department, the current input from the SWWS Compost Facility during its first year of operation was approximately seven tons of total waste. ${ }^{9}$ However, a subject matter expert, John David Naranjo, explained that the facility was only reaching full speed in terms of production during the last few months of the year reported upon. Therefore, he believes that the total input into the composting system is actually more in the range of 35.4 cubic yards per year. ${ }^{10}$ This updated input assumption leads to an expected 40 tons of output yearly instead of the initial numbers recorded. This input is limited to the sludge, carbon sources, and green materials currently used in the composting process and will be used as the expected yearly input in the baseline scenario.

\section{B. Scenario 2: Earth Flow System with Current Input}

The second scenario for this study considers the costs and benefits associated with buying a proposed Earth Flow unit from Green Mountain Technologies and maintaining the same level of inputs into the system as with the current Composting Facility. In this scenario, additional inputs and expansions are not considered. Instead, any potential savings to offset the capital costs of the new system are found solely through increased efficiency in composting. Changes in labor and material costs will be the main form of savings in this analysis.

The composting systems being considered for this particular project are all manufactured by Green Mountain Technologies (GMT). This company, founded in 1992, has been at the forefront of providing high quality, efficient composting solutions for over 20 years. As described by the company's website, one of the main advantages with pursuing a system from GMT is that they offer a comprehensive product line that includes a variety of sizes and pricings. ${ }^{11}$ This allows a necessary flexibility when making the final determination of a technology that best suits LANL's needs. For this analysis, an Earthflow EF-30 model was used for initial considerations.

\footnotetext{
92014 Material and Solid Waste Management Form, Randy E. Vigil

10 John David Naranjo, personal communication, 5/27/2015

${ }^{11}$ http://compostingtechnology.com/about/company-background/
} 


\section{Scenario 3: Earth Flow System with Ideal Input}

The third scenario for this study considers the ideal case for environmental stewardship at LANL. In this scenario, the pursuit of the Zero Waste Initiative goal is in full force and the lab begins a process of gathering and composting food scrap from available sites with the new system. The addition of food scrap to the composting stream will incur benefits by saving money used for waste disposal fees at the landfill. However, there will be additional costs to drive the food waste to TA-46. This cost is somewhat minimized because waste from the three cafeterias considered for this study is already gathered at one site to be weighed before it is sent to the landfill. By merely placing the waste in an available dumpster and shipping it with trucks that are already available and ready for use, the only added cost is the labor associated with the task of shipment itself. ${ }^{12}$ The graphic in Figure 4 visualizes the manner in which wastes are allocated among the three scenarios.

While this third scenario considers a limited scope of inputs, the potential for expansion of waste streams should not be underestimated. Only three of the five cafeteria sites at the lab are currently considered as food waste sources for the composting unit due to ease of access. Furthermore, the food waste determined for this project only consists of pre-consumer food scrap. There are plans to expand to post-consumer food waste in the future. Other waste streams being considered include the large quantity of paper towel waste produced at Los Alamos National Laboratory and the pulverized paper produced by the lab’s burn boxes.

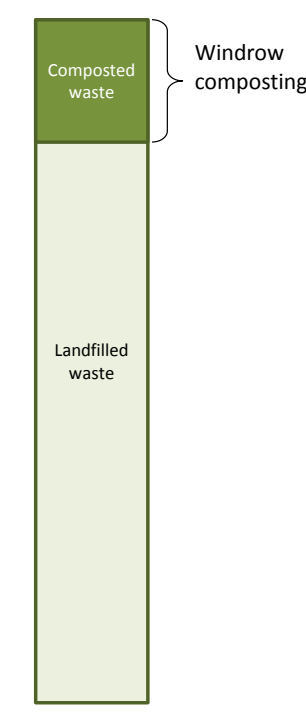

Scenario 1 (baseline)

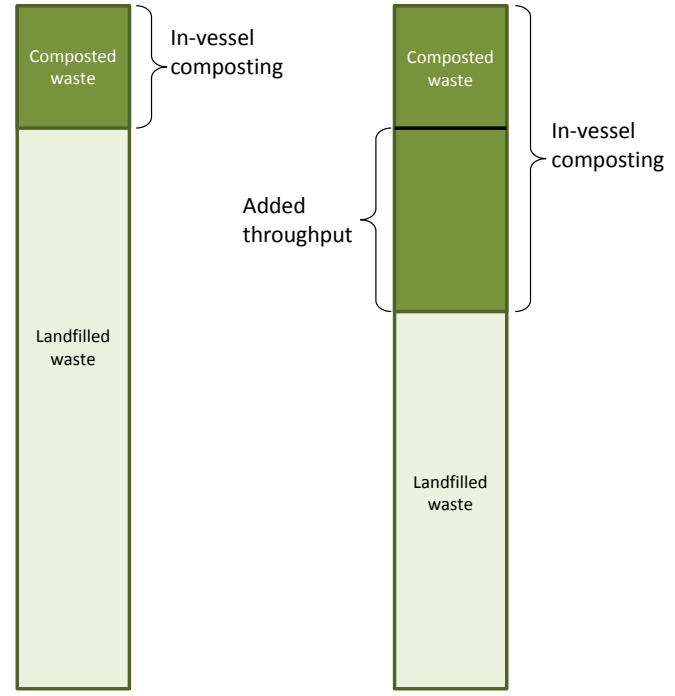

Scenario 2 (same quantity) Scenario 3 (ideal quantity)

Figure 4: Total LANL waste stream as considered for the three basic scenarios. In Scenario 3, certain landfill waste costs are avoided by a diversion of waste to the composting stream. This visual is only meant to show the difference among scenarios, not an accurate representation of quantity of waste.

\footnotetext{
${ }^{12}$ Tim Walker-Foster, personal communication, 8/18/2015
} 


\section{DATA FOR BASELINE SCENARIO}

\section{A. M\&O Costs}

Maintenance and operational costs cover a wide swath of inputs. The maintenance costs being considered for the baseline scenario involve the practical maintenance of equipment essential for the work done at that location. Two workers must spend one hour cleaning the backhoe and Bobcat Front End Loader twelve times a year.

The current system's operational costs are listed below in a number of steps.

Step 1: Beds must be prepared with woodchips and sawdust to enable the air to circulate beneath the piles. This requires two operators for approximately two days of work at four different times throughout the year.

Step 2: Two laborers are needed for one day to pile sludge for drying. This takes one day, 12 times a year.

Step 3: When the compost windrows are being prepared two more operators must spend a day with a backhoe mixing the compost and sawdust, chips, etc. This is determined by the amount of sludge the plant generates but is usually for one bed every month.

Step 4: After compost is mixed, an operator has to check and record temperatures twice a day. The operator also has to ensure the moisture content is correct and make adjustments. This requires one operator for two hours every day.

Step 5: The piles have to be turned and freshened, depending on the weather and temperature at the site. This usually requires two operators for two hours on two separate occasions for each cycle.

Step 6: After a cycle is complete, the finished product must be sampled and tested, then picked up and moved for temporary storage for curing. This involves one operator for one day on each cycle.

\section{B. Materials Costs}

As discussed previously in the study, there are three main inputs necessary for the current compost mixture at the SWWS Composting Facility. They are sludge, woodchips/sawdust as a carbon source, and green waste as a nitrogen source. Sludge is provided by the adjacent wastewater treatment facility. Considering that it is the main product being disposed of as part of this initiative, it has relatively no cost. This is because it has little to no inherent value and would be far more costly to properly dispose of elsewhere. Woodchips and sawdust are transferred from nearby Espanola with minimal actual upfront cost. The cost incurred for this product comes from the three hours of work during which a teamster must handle the load and bring it to the lab from Espanola. The teamster's hourly cost is $\$ 36.38$ per hour with a total of $\$ 109.14$ being spent for each round trip. There will be an assumed 4 round trips per year. The green waste used in the process also has no cost. This is because it is provided on-site by the various grounds crews who tend to the daily upkeep of the lab. These crews are paid to maintain lab property and their 
willingness to provide the composting facility with necessary greenery already provides a degree of savings for the project.

\section{Utilities Costs}

Time was taken during the data gathering process to determine if there were prominent utility costs involved in the composting process. The current composting method uses solar energy, and is separate from the utility grid. The baking process occurs with little interference that would require electric power. The only concern with utilities is that there a necessary moisture content in the windrow that must be provided. Subject matter experts explained that this moisture was wholly provided by two sources. The sludge itself from the wastewater treatment facility provided one source. Any excess moisture necessary for the process came from wastewater at the same facility. This water usage adds no cost to the process because the water is not useful to lab after the treatment process and will not re-enter the system. It would be properly disposed of if it was not used in this process.

\section{DATA FOR SCENARIO 2}

\section{A. Capital/Procurement Costs}

The in-vessel composting system being analyzed for this study is one of a variety of Green Mountain Technologies units. According to subject matter experts at TA-46, an appropriate model is the Earth Flow EF-30 that is approximately 31 feet long and 8.4 feet wide. This will be the model considered for this initial assessment. It has a baseline cost of $\$ 99,895$. This model can handle an estimated 1500 to 2000 pounds (.75 to 1 ton) of material per day and seems like a reasonable choice given the expansion efforts that the Pollution Prevention team wants to eventually reach. Nevertheless, current estimates by SME's at TA-46 assume that total waste input during an average year is only about 40 tons. In contrast, even the smallest of the Earth Flow systems available can handle upwards of 0.4 to 0.5 tons per day for a total of 72 tons over a year (48 weeks). This variety of sizing options will be useful in determining if a less costly system is more applicable to LANL's future needs.

To acquire a composting system, a number of procurement steps are also required. They are listed below.

Step 1: Technical requirements are developed by engineers to determine electricity and water demands, space issues, etc. for the new machinery. This involves three weeks of an engineer's time and one week of input from two workers at the TA-46 Compost Facility to support the engineer.

Step 2: A Subcontract Technical Representative (STR) writes a Request for Proposal (RFP). This requires one week of the STR's time.

Step 3: The STR reviews the proposals and selects the winning vendor. This requires two weeks of the STR's time and two days of support from Randy Vigil at TA-46.

Step 4: The actual purchase of the machine requires three days of STR time. 


\section{B. Installation \& Transition Costs}

This cost variable is composed of the various technical costs of bringing the eventual in-vessel composting unit to LANL and properly installing it at the SWWS Compost Facility. The four steps are Facility Preparation, Installation, Training, and Qualification.

Facility Preparation: A concrete slab must be laid for the composting unit's foundation. The ground is leveled and concrete is poured, costing around \$5,000. A 240 volt electricity line, conduit, and local disconnect must also be connected which will cost $\$ 3,500$. Water is already available for the project so there is no charge there. ${ }^{13}$

Installation: The system will be delivered by truck. Due to size, it will not have skids. A crane will be used to lift it onto a foundation. Only labor is considered because the crane is already onsite. One operator and one rigger will spend one day to put it in place. Four craft workers (two electricians and two pipefitters) will spend one day working on hook ups.

Training: GMT provides two training classes for any personnel operating the machinery. This service is provided on-site for an estimated cost of $\$ 7,500$. Operation training lasts two hours and maintenance training lasts three hours. Seven operators will be trained on this new machinery.

Qualification: There are no qualification costs associated with this project. All personnel are already certified by the state and require no additional qualification.

\section{M\&O Costs}

Much of the usefulness of the various Earth Flow Composting Systems being considered for this project comes from the consistent maceration provided by the unit's automated auger. This function will reduce the time that workers have to engage with the composting process, freeing up their time to engage in other activities and services for the lab. By having one consolidated area for composting, the composting team will not have to use valuable man hours on excess composting activities. Some maintenance costs will be saved due to the consolidated composting area and less usage of machinery for mixing. However, there is a checklist of preventative steps that must be followed to properly maintain the machine. This list is provided by GMT and consists of a number of activities that can be reduced to a yearly total of maintenance hours. Maintenance for the Earth Flow EF-30 system will amount to 108.8 hours of operator time per year. There will also be an additional cost of $\$ 14,380$ every ten years for proper replacement parts. $^{14}$

The operational costs for the new machine are described below.

Step 1: Two Laborers are needed for one day to pile sludge out for drying. This takes one day, 12 times a year. This process remains the same in Scenarios 1 and 2.

Step 2: Dried sludge is then moved to the machine and mixed with the appropriate amount of other inputs. This corresponds to the costs of step 3 of the current scenario but takes only three quarters of the time.

\footnotetext{
${ }^{13}$ Randy Vigil, personal communication, 7/9/2015

${ }^{14}$ Van Calvez, personal correspondence, 8/5/2015
} 
Step 3: After compost is mixed, an operator has to check and record temperatures twice a day. The operator also has to ensure the moisture content is correct and make adjustments. This comes out to one operator for half an hour every day instead of the previous two hours a day.

Step 4: After a cycle is complete, the finished product must be sampled and tested, then picked up and moved for temporary storage for curing. This involves one operator for one day on each cycle. This cost will be the same as the baseline scenario.

\section{Materials Costs}

It is assumed that the type and quantity of materials used in Scenario 2 will be the same as in Scenario 1.

\section{E. Utilities Costs}

The input change that occurs in the realm of utilities is the electrical cost of running the in-vessel composter. While it is not yet known how consistently the system will be used over the course of a year, the system will require electric power to operate its auger and the computer system that helps monitor moisture and aeration. According to a service representative, the system requires $10 \mathrm{~kW}$ hours every day for operation. ${ }^{15}$ This is equivalent to $0.3 \mathrm{MWh} / \mathrm{month}(10 \mathrm{k} \times 30$ days). This consumption of electricity is insignificant with respect to typical LANL operations. An example for comparison is TA-55, which consumes about $1200 \mathrm{MWh} / \mathrm{month}^{16}{ }^{16}$ addition, electricity is not metered for LANL activities. Consequently, electricity cost is not a factor in the business case analysis.

\section{DATA FOR SCENARIO 3}

\section{A. Capital/Procurement/Installation \& Transition/M\&O Costs}

Each of these values in Scenario 3 will be the same as the values determined in Scenario 2. The analysis for both scenarios is considering an Earth Flow EF-30 model.

\section{B. Material Inputs}

The ideal situation for the in-vessel composting system involves a lab-wide initiative to add preconsumer food scraps to the composting stream. Food scrap is a major portion of this initiative because all waste from the many cafeterias around Los Alamos National Laboratory is currently sent to the landfill. Food waste from three cafeterias around the laboratory is currently segregated and brought to one site before being sent to the landfill. Since this activity is already being done, there is no additional cost for the material. The only cost will occur in the realm of transportation which will be discussed later. According to Aramark representatives, there are an estimated 700 pounds of food waste per week that can be brought into the composting stream. ${ }^{17}$ This would lead to approximately 35,000 pounds over the course of a year (assuming 50 weeks of waste). This will generate a yearly input of 17.5 tons for the composting system.

\footnotetext{
${ }^{15}$ Van Calvez, personal communication, 7/31/2015

${ }^{16}$ Booth, Steven R., "Revised Final Report, Data Call to Support the Surplus Plutonium Disposition Supplemental Environmental Impact Statement,” LA-UR-12-26497, Version 3, April 2013, page 27.

${ }^{17}$ Emma Rose Cohen, personal communication, 5/28/2015
} 
Cost of composting inputs under Scenario 3 change little in comparison to the other two scenarios. All of the new inputs are waste items that would usually be transported to a landfill. Since they are instead being moved to a different location, any additional cost for their transportation to TA-46 is negligible. There is no change in the cost of shipping woodchips from Espanola.

\section{Transportation Costs}

Adding food waste to the composting stream incurs a significant cost. While the infrastructure necessary for adding this waste to the composting stream already exists (i.e. the waste is already segregated and grouped in one location), there are still costs to move the waste to TA-46. According to an SME, this will amount to two hours of two teamsters to ship the waste every week. As determined earlier, the cost of a teamster is $\$ 36.38$ per hour. When considering 50 weeks of pickups per year, the total transportation cost would amount to \$7,276 per year.

\section{Waste Disposal Fees}

Unlike Scenario 2 which regards only the current input stream, the added materials of Scenario 3 help avoid costs due to landfill diversion. Currently, waste shipped to the landfill costs incurs a \$65 tipping fee for every ton of waste. The food scrap waste taken out of the landfill stream amounts to about 17.5 tons every year. This leads to an avoidance of $\$ 1.4 \mathrm{k}$ each year in tipping fees due to diversion. Waste trucking costs do not change because the diversion is insignificant in terms of total LANL annual solid waste.

\section{E. Additional Throughput}

The amount of throughput under Scenario 3 is changed in a way that reduces the costs associated with dumping waste. Total costs for composting are assumed to remain relatively unchanged because of a lack of cost differences between Scenario 2 and 3. SMEs at TA-46 have discussed having a similar operating schedule for the new machinery regardless of input levels.

\section{RESULTS}

The results of this business case are presented over the following pages. Table 1 provides assumptions that are necessary for determining the lifecycle costs of installing an Earth Flow EF30 system. Standard labor rates are used with an SME-established work schedule to generate maintenance and operational costs for the different scenarios. Full costs for purchasing and installing the system on LANL grounds are also computed. Table 2 presents the lifecycle costs and benefits of an Earth Flow EF-30 system using current input levels. The red half of the graphic shows the costs incurred by buying and operating the new system. The green half reflects the costs from the current scenario that are avoided by making the switch to the new scenario. The difference between the accumulated benefits and costs is recorded in the blue column as the net present value of the project. For Scenario 2, the project breaks even in its fifth year and has an eventual net present value of $\$ 482 \mathrm{~K}$. Table 3 presents the lifecycle costs and benefits of an Earth Flow EF-30 system in an ideal setting with food scrap as an added input. For Scenario 3, the project breaks even in its sixth year and has an eventual net present value of $\$ 370 \mathrm{~K}$. Under both scenarios, the project has a positive net present value. 


\section{Table 1}

\section{Assumptions and Factors for Life Cycle Analysis of}

Earth Flow EF-30 System

\begin{tabular}{|c|c|}
\hline Assumptions & Comments \\
\hline Real Discount Rate $\{1\}$ & 0.01 \\
\hline Engineer, SLR & $\$ 87$ R\& D Engineer/G\&A code \\
\hline Group Leader, SLR & $\$ 75$ \\
\hline Operator, SLR & $\$ 46$ Rate without burdens \\
\hline Foreman, SLR & $\$ 49$ Rate without burdens \\
\hline Maintenance/Craftsperson TEC, SLR & $\$ 75$ AKN \\
\hline Other Support, SLR (e.g., procurement) & $\$ 75$ \\
\hline Productive Hours per year & 1730 for R\&D Eng \\
\hline \multicolumn{2}{|l|}{ New Machine } \\
\hline Equipment Cost (\$) & 99,895 \\
\hline Procurement Support Cost (\$) $\{2\}$ & 26,129 \\
\hline Facility Preparation (\$) $\{3\}$ & 32,745 \\
\hline Installation (\$) $\{4\}$ & 3,370 \\
\hline Training (\$) $\{5\}$ & 9,121 \\
\hline Qualification (\$) $\{6\}$ & 0 \\
\hline \multicolumn{2}{|l|}{ Maintenance \& Operation } \\
\hline Maintenance, Scenario 1 (\$ per year) $\{7\}$ & 1,111 \\
\hline Maintenance, Scenarios $2 \& 3$ (\$ per year) $\{8\}$ & 5,593 extra 14380 every 10 years \\
\hline Operation, Scenario $1\{9\}$ & 65,256 \\
\hline Operation, Scenarios $2 \& 3\{10\}$ & 25,141 \\
\hline Materials Costs & 438 \\
\hline Transport Costs $\{11\}$ & 7,276 \\
\hline
\end{tabular}

\{1\} Source: 10-year real discount rate, OMB Circular No. A-94, Appendix C (Revised December, 2013).

\{2\} Development of Tech requirements, one engineer for three weeks with one week of support from two workers. STR write a RFP, one week of STR time. STR reviews the proposal and selects winning vendor, two weeks of STR time. Randy Vigil provides support for two days in this step. Actual purchase, three days of STR time.

\{3\} Concrete slab must be laid and leveled for foundation, $\$ 5,000$. 240 volt electricity line, conduit, and local disconnect must be connected, $\$ 3,500$. Two operators will need to work on trenching and potholing on two different occasions for three days. Further setup will involve four days of four carpenters working, two days of four masons working, and three days of three pipefitters working.

$\{4\}$ One operator and one rigger will spend one day putting the system in place. Four craft workers will spend one day working on hook ups.

$\{5\}$ Seven operators will take 5 hours of training on the machinery. This training will have a blanket cost of $\$ 7,500$.

$\{6\}$ There will be no qualification costs

$\{7\} 2$ operators for one hour cleaning a backhoe and bobcat 12 times a year.

$\{8\}$ Assumes half cost of maintenance for Scenario 1 due to less backhoe and bobcat usage. Yearly Maintenance for Earthflow EF-30 will amount to 108.8 hours per year of Operator time

$\{9\}$ Beds are prepared by two operators for two days four times throughout the year. Sludge is piled out for drying 12 times a year, this requires two laborers for one day. An operator and a foreman must spend a day with a backhoe mixing compost and other inputs. This happens 12 times a year. One operator must check and record temperatures daily, requiring two hours every day for an expected 50 weeks of operation. Piles must be turned for freshening, requires two operators for two hours 24 times a year. The finished product must be picked up and moved for temporary storage for curing, requires one operator for one day 12 times a year.

$\{10\}$ Beds are prepared by two operators for two days four times throughout the year. Dried sludge is then moved to the system and mixed, requiring an operator and a foreman for 0.75 of a day 12 times a year. One operator must check and record temperatures daily, requiring 0.5 hour every day for an expected 50 weeks of operation. The finished product must be picked up and moved for temporary storage for curing, requiring one operator for one day 12 times a year.

$\{11\}$ Transportation of food waste requires two teamsters for two hours over the course of 50 weeks. Teamsters cost $\$ 36.38$ per hour. 
Table 2

Life-Cycle Benefits and Costs of Scenario 2 Compared to Scenario 1

Investment Costs, Earth Flow Composting System Costs Savings (Benefits) (\$)

Waste Disposal Cumulative

Capital Installation and

Total Annual Discounted Total

Waste Disposal

Transporation and Total Annual Discounted Total Discounted Cash

Year Cost/Procurement Transition

M\&O Materials Utilities

Cost

Annual cost

M\&O Materials Utilities Tipping Fees) Benefits

2015

$30,734 \quad 438$

$30,734 \quad 438$

$\begin{array}{ll}30,734 & 438 \\ 30,734 & 438\end{array}$

$31,172 \quad 30,863 \quad 66,367$

31,172

$30,558-66,367$

$31,172 \quad 30,255 \quad 66,367$

2018

31,172

30,255

66,367

$31,172 \quad 29,659 \quad 66,367$

$30,734 \quad 438$

$\begin{array}{ll}30,734 & 438 \\ 45,114 & 438\end{array}$

31,172

$29,365 \quad 66,367$

$\begin{array}{lll}45,552 & 29,075 & 66,367 \\ 32,066 & 66,367\end{array}$

$\begin{array}{llllll}30,734 & 438 & 0 & 31,172 & 28,502 & 66,367\end{array}$

2024

2024
2025
2026

31,172

28,220

438
438
438
438
438
438
438
438
438
438
438
438
438
438
438
438
438
438
438
438
438
9,198

0
0
0
0
0
0
0
0
0
0
0
0
0
0
0
0
0
0
0
0
0

(a)

0
0
0
0
0
0
0
0
0
0
0
0
0
0
0
0
0
0
0
0
0

0
0
0
0
0
0
0
0
0
0
0
0
0
0
0
0
0
0
0
0
0

$66,805-66,805$

$-135,627$

$\begin{array}{lll}66,805 & 66,144 & -100,347 \\ 66,805 & 65,489 & -65,416\end{array}$

$66,805 \quad 65,489 \quad-65,416$

$\begin{array}{lll}66,805 & 64,840 & -30,831\end{array}$

$\begin{array}{rr}66,805 & 64,198 \\ 66,805 & 3,412\end{array}$

$66,805 \quad 63,563 \quad 37,316$

$\begin{array}{rrr}66,805 & 62,933 & 70,883 \\ 66,805 & 62,310 & 104,119\end{array}$

$\begin{array}{lll}66,805 & 61,693 & 123,746\end{array}$

$\begin{array}{lll}66,805 & 61,082 & 156,327\end{array}$

$60,478=188,585$

$\begin{array}{lll}66,805 & 59,879 & 220,523 \\ 66,805 & 59,286 & 252,16\end{array}$

$\begin{array}{lll}66,805 & 59,286 & 252,146 \\ 66,805 & 58,699 & 283,455\end{array}$

$66,805 \quad 58,118 \quad 314,455$

$\begin{array}{lll}66,805 & 57,542 & 345,147\end{array}$

$66,805 \quad 56,973 \quad 375,536$

$\begin{array}{lll}66,805 & 56,409 & 405,623\end{array}$

$\begin{array}{lll}66,805 & 55,850 & 435,413\end{array}$

$\begin{array}{lll}66,805 & 55,297 & 453,005\end{array}$

$\begin{array}{rr}66,805 & 54,750 \\ 1,402,904 & \mathbf{1 , 2 7 2 , 3 3 7}\end{array}$

482,208 
Table 3

Life-Cycle Benefits and Costs of Scenario 3 Compared to Scenario 1

Investment Costs, Earth Flow Composting System Costs Savings (Benefits)(S)

Waste Disposal Cumulative

Capital Installation and Transport $\quad$ Total Annual Discounted Total

Cost/Procurement Transition MEO Materials Costs Utilities

\begin{tabular}{|c|c|c|c|c|c|c|c|c|c|c|c|c|c|c|c|}
\hline Year & $\begin{array}{c}\text { Capital } \\
\text { Cost/Procurement }\end{array}$ & $\begin{array}{l}\text { Installation and } \\
\text { Transition }\end{array}$ & $M \& O$ & Materials & $\begin{array}{l}\text { Transport } \\
\text { Costs }\end{array}$ & Utilities & $\begin{array}{l}\text { Total Annual } \\
\text { Cost }\end{array}$ & $\begin{array}{l}\text { Discounted Total } \\
\text { Annual Cost }\end{array}$ & M\&O & Materials & Utilities & $\begin{array}{l}\text { (Transporation and } \\
\text { Tipping Fees) }\end{array}$ & $\begin{array}{l}\text { Total Annual } \\
\text { Benefits }\end{array}$ & $\begin{array}{l}\text { Discounted Total } \\
\text { Annual Benefits }\end{array}$ & $\begin{array}{c}\text { Discounted Cash } \\
\text { Flow }\end{array}$ \\
\hline 2015 & 126,024 & 45,236 & 30,734 & 438 & 7,276 & & 209,708 & 209,708 & 66,367 & 438 & & 1,400 & 68,205 & 68,205 & $-141,503$ \\
\hline 2016 & & & 30,734 & 438 & 7,276 & & 38,448 & 38,067 & 66,367 & 438 & & 1,400 & 68,205 & 67,530 & $-112,040$ \\
\hline 2017 & & & 30,734 & 438 & 7,276 & & 38,448 & 37,690 & 66,367 & 438 & & 1,400 & 68,205 & 66,861 & $-82,870$ \\
\hline 2018 & & & 30,734 & 438 & 7,276 & & 38,448 & 37,317 & 66,367 & 438 & & 1,400 & 68,205 & 66,199 & $-53,988$ \\
\hline 2019 & & & 30,734 & 438 & 7,276 & & 38,448 & 36,948 & 66,367 & 438 & & 1,400 & 68,205 & 65,544 & $-25,392$ \\
\hline 2020 & & & 30,734 & 438 & 7,276 & & 38,448 & 36,582 & 66,367 & 438 & & 1,400 & 68,205 & 64,895 & 2,921 \\
\hline 2021 & & & 30,734 & 438 & 7,276 & & 38,448 & 36,220 & 66,367 & 438 & & 1,400 & 68,205 & 64,252 & 30,953 \\
\hline 2022 & & & 30,734 & 438 & 7,276 & & 38,448 & 35,861 & 66,367 & 438 & & 1,400 & 68,205 & 63,616 & 58,708 \\
\hline 2023 & & & 30,734 & 438 & 7,276 & & 38,448 & 35,506 & 66,367 & 438 & & 1,400 & 68,205 & 62,986 & 86,188 \\
\hline 2024 & & 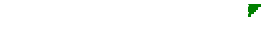 & 45,114 & 438 & 7,276 & & 52,828 & 48,303 & 66,367 & 438 & & 1,400 & 68,205 & 62,363 & 100,248 \\
\hline 2025 & & & 30,734 & 438 & 7,276 & & 38,448 & 34,806 & 66,367 & 438 & & 1,400 & 68,205 & 61,745 & 127,187 \\
\hline 2026 & & & 30,734 & 438 & 7,276 & & 38,448 & 34,462 & 66,367 & 438 & & 1,400 & 68,205 & 61,134 & 153,859 \\
\hline 2027 & & & 30,734 & 438 & 7,276 & & 38,448 & 34,121 & 66,367 & 438 & & 1,400 & 68,205 & 60,528 & 180,266 \\
\hline 2028 & & & 30,734 & 438 & 7,276 & & 38,448 & 33,783 & 66,367 & 438 & & 1,400 & 68,205 & 59,929 & 206,413 \\
\hline 2029 & & & 30,734 & 438 & 7,276 & & 38,448 & 33,448 & 66,367 & 438 & & 1,400 & 68,205 & 59,336 & 232,300 \\
\hline 2030 & & & 30,734 & 438 & 7,276 & & 38,448 & 33,117 & 66,367 & 438 & & 1,400 & 68,205 & 58,748 & 257,932 \\
\hline 2031 & & & 30,734 & 438 & 7,276 & & 38,448 & 32,789 & 66,367 & 438 & & 1,400 & 68,205 & 58,167 & 283,309 \\
\hline 2032 & & & 30,734 & 438 & 7,276 & & 38,448 & 32,465 & 66,367 & 438 & & 1,400 & 68,205 & 57,591 & 308,435 \\
\hline 2033 & & & 30,734 & 438 & 7,276 & & 38,448 & 32,143 & 66,367 & 438 & & 1,400 & 68,205 & 57,021 & 333,313 \\
\hline 2034 & & 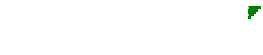 & 45,114 & 438 & 7,276 & & 52,828 & 43,728 & 66,367 & 438 & & 1,400 & 68,205 & 56,456 & 346,041 \\
\hline 2035 & & & 30,734 & 438 & 7,276 & & 38,448 & 31,510 & 66,367 & 438 & & 1,400 & 68,205 & 55,897 & 370,428 \\
\hline Total & 126,024 & 45,236 & 674,173 & 9,198 & 152,796 & & $1,007,427$ & 928,573 & $1,393,706$ & $9,198^{r}$ & & 29,400 & $1,432,304$ & $1,299,001$ & \\
\hline
\end{tabular}

Tippin Discounted Total Discounted Cash 


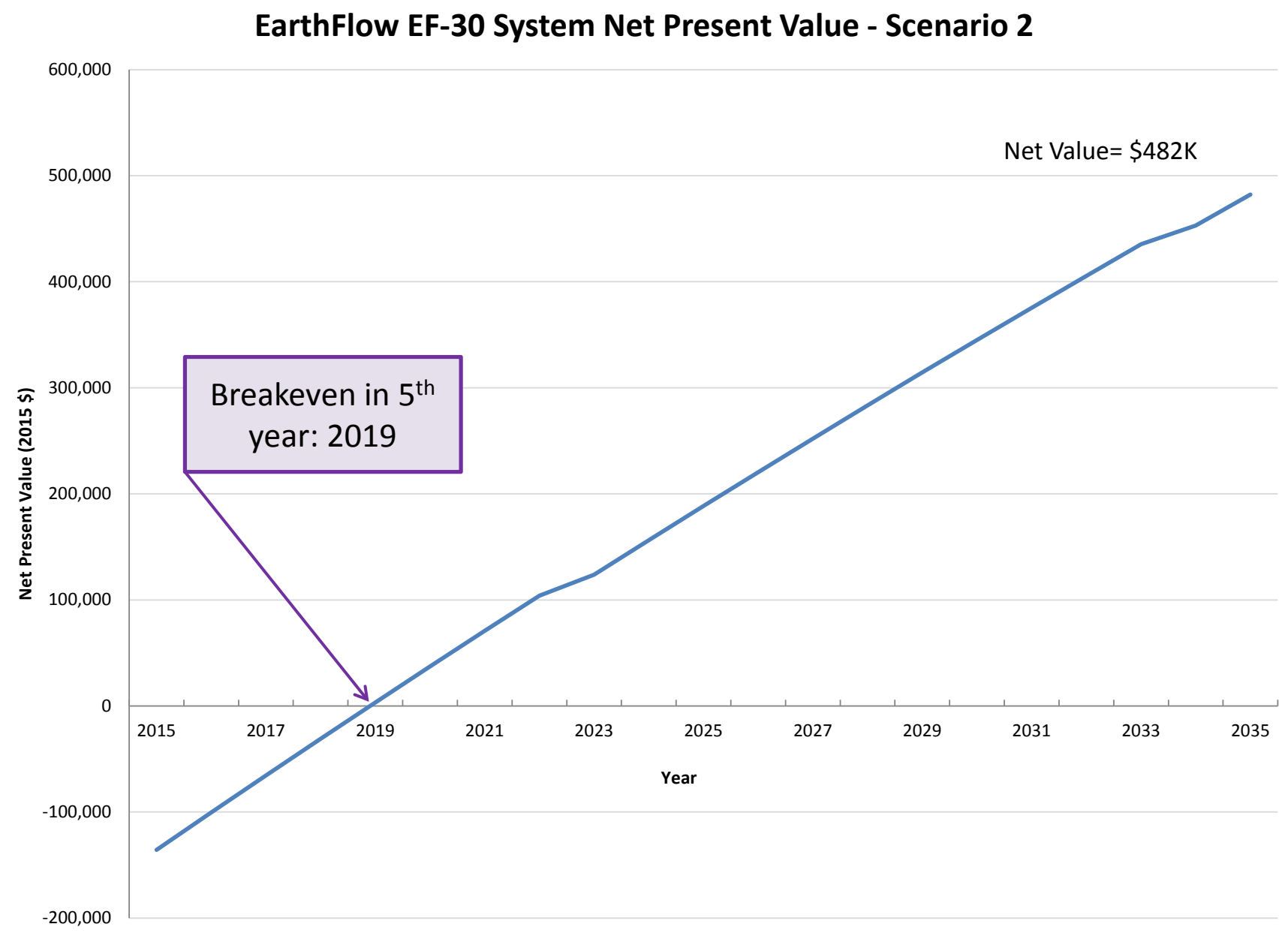

Figure 5: The payback period for installing an Earth Flow EF-30 System at the SWWS Compost Facility in Scenario 2 is in the fifth year, with a \$482k savings over a 20 year project life. 


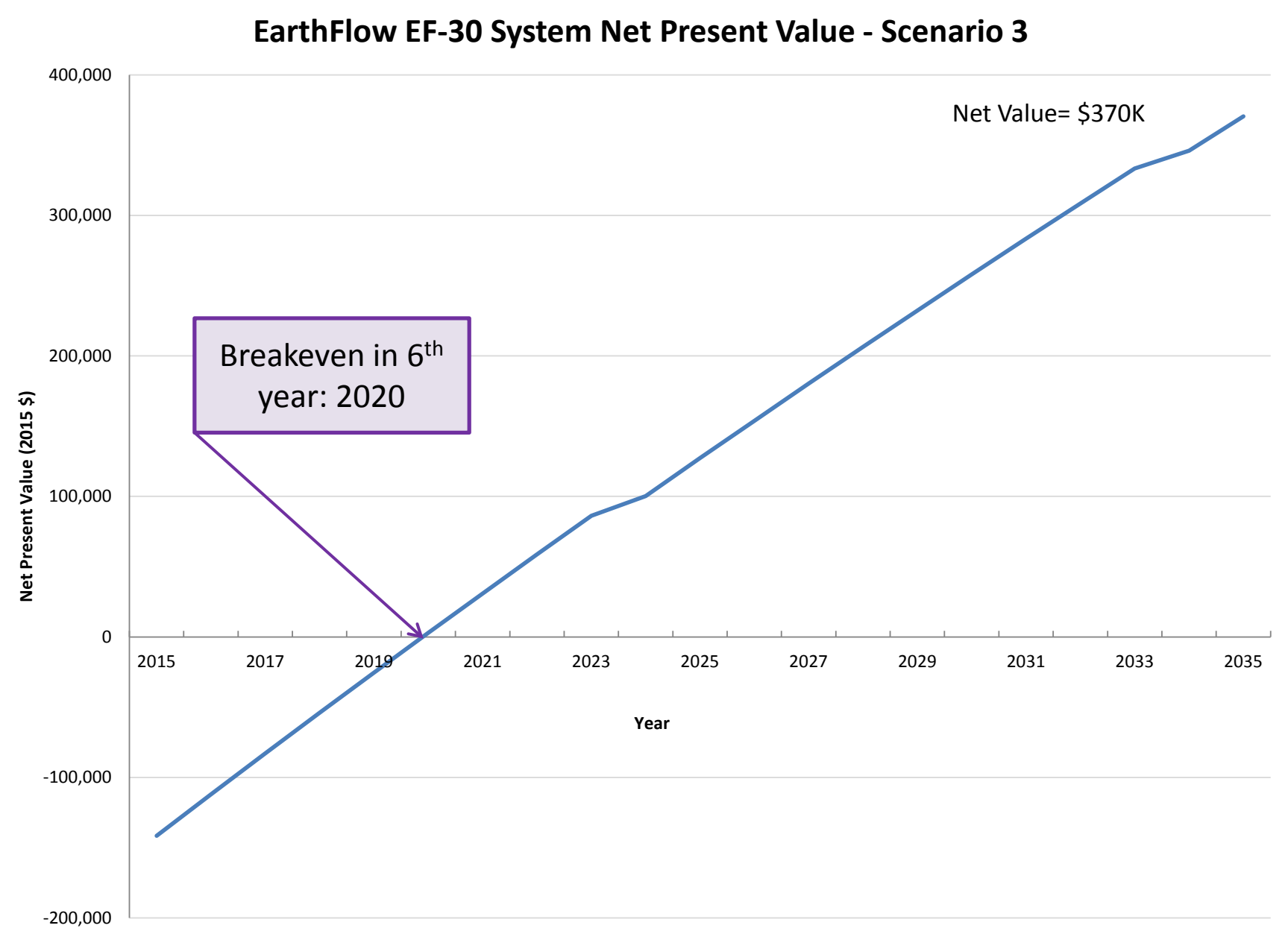

Figure 6: The payback period for installing an Earth Flow EF-30 System at the SWWS Compost Facility in Scenario 3 is in the sixth year, with a \$370k savings over a 20 year project life. 
For more information, please contact:

\section{Timothy Dinehart}

Process Modeling and Analysis (AET-2)

505-667-2242

tdinehart@lanl.gov 